Journal Of Al-Azhar University Engineering Sector

VOL. 14, NO. 50, JANUARY, 2019, 75-86

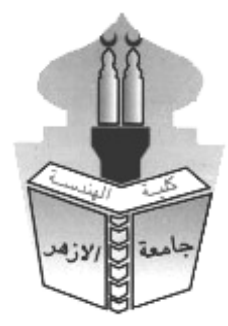

\title{
VOLUME CALCULATION OF IRREGULAR OBJECT USING MULTIPLE SOFTWARE PACKAGES
}

\author{
Mostafa H. A. Mohamed \\ Al-Azhar University, Faculty of Engineering, Civil Engineering Department, Cairo, Egypt.
}

\begin{abstract}
Volume calculation is needed in many civil engineering projects. Recently, several software packages are used in volume calculation such as Civil3D, Surfer, and GIS softwares. The main objective of the presented work is to explain how volumes of cut and fill using these software packages can be calculated. Moreover, methods of interpolation using different software packages are investigated. The test site used in this research is located at Ain El Sokhna- Zafarana Road, Red Sea, Egypt with surface area around $126,000 \mathrm{~m}^{2}$. Methods of the data gridding and precision of volume calculation based on Civil3D, Surfer, and ArcMap software packages are studied. Distribution and intensity of points are important factors in modeling earth surfaces. Interpolation methods employing different mathematical models are used to obtain 3D models of terrain surfaces. The 3D surface and volume are calculated by using 12 different interpolation methods. The accuracy of the volume calculation depends on the appropriateness of the interpolation method used in creating 3D models. The calculated net volumes by Inverse Distance, Modified Shepard's Method, Nearest Neighbor, Kriging, and Triangulation with Linear Interpolation methods yielded closed results compared with other methods. In conclusion, the accuracy of volume determination of irregular bodies is dependent on the interpolation of modeling and computational method capable of approximating the irregular body and thus represents its actual, real shape.
\end{abstract}

Keywords: Volume calculation, Interpolation methods, Gridding data, Civil3D, Surfer, ArcMap.

\footnotetext{
الملخص العربي

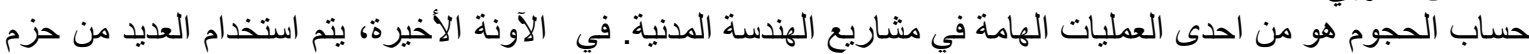

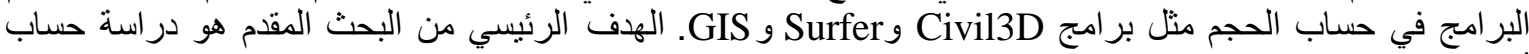

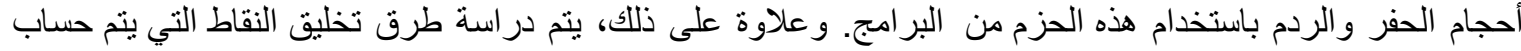

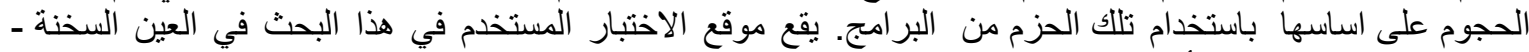

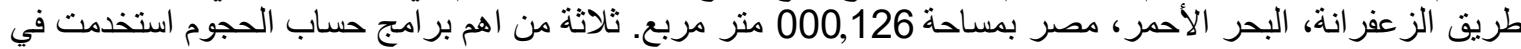
ذللك البحث و هي Civil3D, Surfer, and ArcMap8. نم حساب السطح ثنلاثي الابعاد وبالتالي الحجوم باستخدام 12

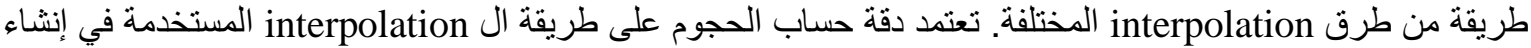
Inverse Distance, Modified Shepard's النماذج ثلاثنية الأبعاد. وقد كانت النتائج للحجم الكلى المحسوب باستخدام Method, Nearest Neighbor, Kriging, and Triangulation with linear interpolation مقارنة بالطرق الأخرى. ونخلص من ذللك ان حساب الحجوم للأجسام غير المنتظمة تعتمد في الأساس على طريقة ال interpolation
} 


\section{INTRODUCTION}

The choice of the interpolation method and its parameters depend on many factors: for example, the type of interpolated phenomenon, the character of its surfaces (horizontal and elevation segmentation, break lines etc.) or the purpose of digital modeling (Fencik et al., 2005). Mathematical formulation of a surface which either exists in reality or is theoretically produced is referred to as surface modeling. This technology is used in various fields of science such as mathematics or statistics. The irregular geometric form of the physical earth makes the formulation of a surface through mathematical functions difficult and inaccurate.

Volume is defined as the amount of material occupying a certain space, expressed in cubic units. Data obtained from surveying works are used to calculate earthwork quantities. Values of volume in terrains that do not have regular geometric structure can be obtained more accurately by using 3D models of surfaces with respect to developing technology (Y1lmaz, 2007). There are several methodologies for volume calculation. Each method is different in proper selection of instrumentation and method of data processing. These methods include contact, non-contact surveying systems prismless and robotic total stations, photogrammetric cameras, terrestrial and aerial laser scanners (Pukanská et al., 2008). Civil 3D, surfer, and GIS packages are used by civil engineers, geologist and surveyors to perform the detail design of roads, open-pit mining, dams, garbage dumps, land rehabilitation, civil general design and so on. These softwares used to perform the complete land design and automatically make the calculation of the cut and fill volumes inside a bounded area.

The present study investigates the calculation of irregular models constructed using different interpolation methods. 3D models were formed according to different interpolation methods using several softwares and the volumes were calculated and compared.

\section{TEST SITE AND DATA USED}

Irregular surface presented in figure- 1 is selected as testing site for surveying and subsequent analysis of calculations of volumes. The site is located at Ain El SokhnaZafarana Road, Red Sea, Egypt. Its surface area is around $126000 \mathrm{~m}^{2}$. The test site was surveyed using Topcon total station. Surfer, civil 3D, and GIS software packages were used for processing the surveying data.

Surfer software is effective tool for producing digital maps. The spatial terrain model is based on the points with $\mathrm{X}, \mathrm{Z}, \mathrm{Y}$ coordinates registered in ASCII-type files with DAT extension. Based on the coordinate of these points a network of GRID type points is created and registered in files with GRD extension. In case of using the irregular methods the points are connected as triangles. Each triangle is a surface which is used for volume computation. Also, this technique is used in other software packages such as Civil3D and ArcMap (Rick Ellis, 2012 and Mike Price, 2002). 


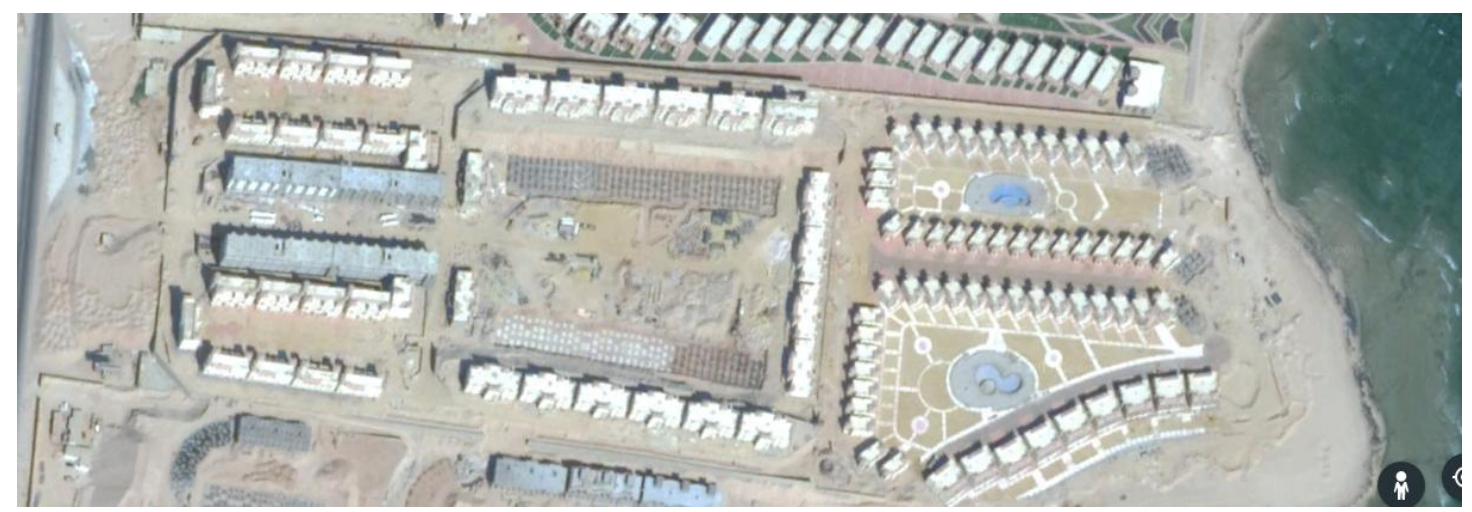

Fig. 1. Image of test site.

\section{INTERPOLATION METHODS}

Data in grid format is suitable for processing volume calculation for irregular object. The values at the grid nodes can be determined by taking field observation at the node locations. However, in practice this is seldom convenient and it is more likely to have data that has been collected at random locations, or which has been collected at a relatively high sample data density along more widely separated parallel lines. The process of gridding takes XYZ data and interpolates the readings to determine the $\mathrm{Z}$ values at the nodes of a grid as shown in figure- 2 .

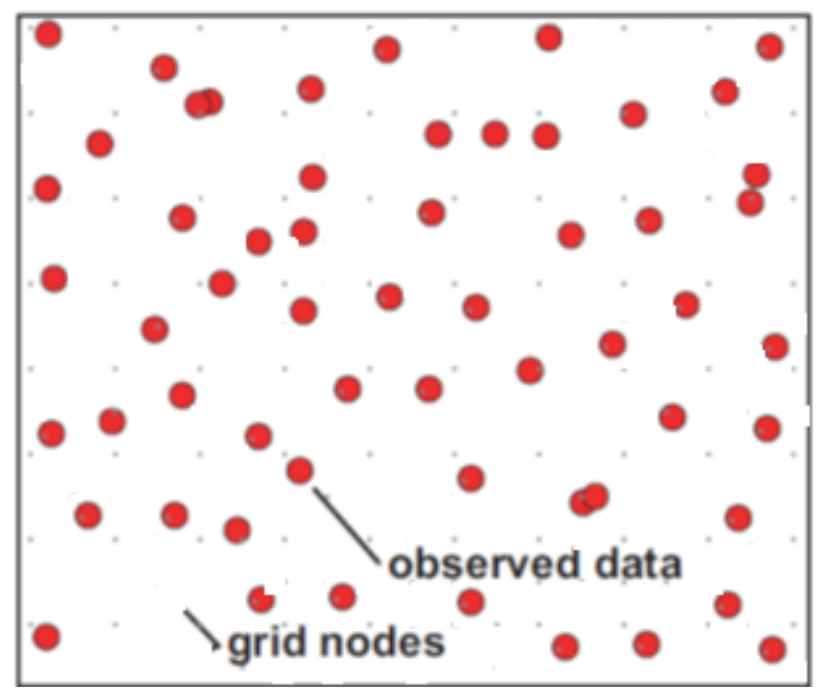

Fig. 2. Gridding process.

Interpolation methods allow creating a surface on the base of sample points and predicting of values in all point of territory. There are many interpolation methods which produce different results using the same data. The input data are similar in any program: Civil3D, Land Desktop, InRoads, ArcGIS, surfer, etc. and includes point data for Digital Terrain Modeling consist of individual discrete $\mathrm{X}, \mathrm{Y}$ and $\mathrm{Z}$ locations, without connecting features between them. Breaklines data are also referred to as faults, or features. Breaklines, as 
used in this context, represent the linear edges of site features along which there is a noticeable change in grade.

In Surfer 8 software, grid surfaces of object can be generated from the X,Y,Z coordinates of object surface using ten interpolation methods. The following explain and discuss briefly some interpolation methods which are commonly used in geomorphologic and geodesic studies.

\section{I- INVERSE DISTANCE WEIGHTING}

The Inverse Distance Weighting method is based on a quite simple algorithm. This method is particularly used in defining continuously changing data on the same area. This method is a weighted average interpolator, which can be either exact or smoothing. With inverse distance to a power, data are weighted during interpolation such that the influence of one point relative to another declines with distance from the grid node (Yang et al., 2004). Force parameters indicate how the weight effect decreases as the distance increases from a grid corner. For a relatively smaller force the weights are more evenly distributed between reference points. The equations (1) and (2) are used for inverse distance method.

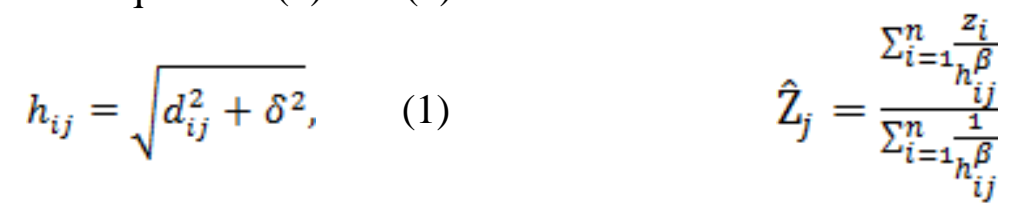

Where $\boldsymbol{h} \boldsymbol{i} \boldsymbol{j}$ is the effective separation distance between grid node $j$ and neighbouring point $i$,

$\hat{\mathrm{Z}}_{j}$ is the interpolated $\mathrm{Z}$ value for grid node $\mathrm{j}$,

$Z_{i}$ is the neighbouring elevation of points $i$,

$d_{i j}$ is the distance between the grid node $\mathrm{j}$ and the neighbouring point $\mathrm{i}$,

$\beta$ is the weighting power (the power parameter), and

$\delta$ is the smoothing parameter (Y1lmaz, 2007).

\section{II-KRIGING}

Kriging is one of the more flexible methods and is useful for gridding almost any type of data set. The most popular Ordinary Kriging can predict an unknown value as shown with the equation (3) with the linear summation of known surrounding values in order to know the values of points of interest, and the error variance or Ordinary Kriging variance is expressed as equation (4) (Jang et al., 2015).

$$
\begin{aligned}
& z^{\prime}\left(x_{o}\right)=\sum_{i=1}^{n(x)} \lambda_{i} Z\left(X_{i}\right) \\
& \sigma_{o k}^{2}=E\left[z\left(x_{o}\right)^{2}-z^{\prime}\left(x_{o}\right)^{2}\right]
\end{aligned}
$$

Where, $z^{\prime}\left(x_{0}\right)$ is a predicted $z$ value of point $\left(x_{0}\right)$ position is known, $Z\left(X_{i}\right)$ is the base data value at the location $X_{i}$,

$\left(\lambda_{i}\right)$ is a weight of base data value, $\left(\sigma_{o k}^{2}\right)$; is the Ordinary Kriging variance; and 
$n(x)$ is the number of used data to predict the Kriging.

Kriging requires to minimize the error between predicted and actual values and unbiased the predicted values in order to decide the weight. Bias is defined as the difference between the factor average of population and average of estimation to predict the factor of the population, and it is regarded unbiased when the difference is none. In addition, the sum of weight , $\lambda_{i}$ must be 1 to meet the unbiased condition (Jang et al., 2015).

\section{III- MINIMUM CURVATURE}

A minimum curvature surface is the smoothest possible surface that will fit the given data values. First, this method estimates grid values at the nodes of a coarse grid (usually 8 times the final grid cell size) based on the inverse distance average of the actual data within a specified search radius. If there is no data within that radius, the average of all data points in the grid is used. An iterative method is then employed to adjust the grid to fit the actual data points nearest the coarse grid nodes. Once an acceptable fit is achieved, the coarse cell size is divided by 2 and the same process is repeated using the coarse grid as the starting surface. This is process repeated until the minimum curvature surface is fit at the final grid cell size. Minimum curvature generates the smoothest possible surface while attempting to fit data as closely as possible (Nikolova and Vassilev, 2006). Equation (5) is used in the interpolation process with the minimum curvature algorithm (Smith and Wessel, 1990):

$$
\left(1-, T_{i}\right) \nabla^{2}\left(\nabla^{2} Z\right)-\left(T_{i}\right) \nabla^{2} Z=0
$$

Where $\nabla^{2}$ is the Laplacian operator,

$Z$ is the interpolated value,

$T_{i}$ is the internal tension.

\section{IV- MODIFIED SHEPARD'S METHOD}

The interpolation method based on the inverse distance weighted is sometimes called Shepard's method (William and Thacker, 2009). (Franke and Nielson, 1980) developed a modification that eliminates the deficiencies of the original Shepard's method. They modified the weight function $W_{k}(x)$ to have local support and hence to localize the overall approximation, and replaced $\mathrm{fk}$ with a suitable local approximation ${ }_{k}(x)$. This method is called the local modified Shepard method and has the general form:

$$
\tilde{f}(x)=\frac{\sum_{k=1}^{\mathrm{n}} W_{k}(x) p_{k}(x)}{\sum_{k=1}^{\mathrm{m}} W_{k}(x)}
$$

Where $P_{k}(x)$ is a local approximant to the function $\tilde{f}(x)$ centered at $\mathrm{x}$, with the property that $P_{k}(x)=\mathrm{f}(\mathrm{k})$. The choice for the weight functions $W_{k}(x)$ used by (Renka, 1988) was suggested by (Franke and Nielson, 1980) and can be calculated using equation (7)

$$
W_{k}(x)=\left[\frac{R_{w}^{(k)}-d_{k}(x)}{R_{w}^{(k)} d_{k}(x)}\right]^{2}
$$

Where $R_{w}^{(k)}$ is the distance from the interpolation point to the most distant scatter point, $d_{k}(x)$ is is the distance from the interpolation point to scatter point.

\section{V-NATURAL NEIGHBOR}

Natural Neighbor method is based on the average mean, is similar to the Inverse Distance Weighting method. This method uses the distance dependent weights of reference points to the grid corner. The data on the reference points with irregular distribution are classified and the interpolation process is completed using the Triangular Irregular Network (TIN) 
functions without any need for custom-defined parameters. Two main techniques are used, first, a triangulation is performed where each reference point constitutes the vertex of a triangle. Then, the convex spaces are defined so that there are a minimum number of triangle sides for each point. The general form of this surface representation is given by equation (8) (Y1lmaz, 2007):

$$
G(x, y)=\sum_{i=1}^{n} w_{i} f\left(X_{i}, y_{i}\right)
$$

Where, $\boldsymbol{G}(\boldsymbol{x}, \boldsymbol{y})$ is the natural neighbor estimation at $(x, y)$, $n$ is the number of nearest neighbors used for interpolation, $f\left(X_{i}, y_{i}\right)$ is the observed value at $\left(X_{i}, y_{i}\right)$, and $w_{i}$ is the weight associated with $f\left(X_{i}, y_{i}\right)$.

\section{VI- NEAREST NEIGHBOR}

The nearest neighbor method assigns the value of the nearest point to each grid node. This method is useful when data are already evenly spaced. Alternatively, in cases where the data are nearly on a grid with only a few missing values, this method is effective for filling in the holes in the data. This method predicts the attributes of unsampled points based on those of the nearest reference point and is best for qualitative data, where other interpolation methods are not applicable (Burrough and McDonnell, 1998).

\section{VII-POLYNOMIAL REGRESSION}

Polynomial Regression is used to define large-scale trends and patterns in the data. Polynomial Regression is not really an interpolator because it does not attempt to predict unknown $\mathrm{Z}$ values. There are several options you can use to define the type of surface from equation (9) to (12) (Y1lmaz, 2007).

Simple planar surface: $Z(x, y)=a+b x+c y$

Bi-linear surface: $z(x, y)=a+b x+c y+d x y$

Quadratic surface: $z(x, y)=a+b x+c y+d x^{2}+e x y+f y^{2}$

Cubic surface:

$$
Z(x, y)=a+b x+c y+d x^{2}+e x y+f y^{2}+g x^{3}+h x^{2} y+i x y^{2}+j y^{3}
$$

Where. $a, b, \ldots j$ are the Polynomial parameters.

\section{VIII- RADIAL BASIS FUNCTION INTERPOLATION}

Radial basis function methods for interpolation to values of a function of several variables are particularly useful when the data points are in general positions, but hardly any sparsity occurs in the matrix of the linear system of interpolation equations (Faul and Powell, 1999). The functions define the optimal set of weights to apply to the data points when interpolating a grid node (Louie, 2001). In this case the surface is calculated on the base of the following general equation (13):

$$
F\left(d_{i j}\right)=\sqrt{d_{i j}^{2}+r^{2}}
$$

Where $F\left(d_{i j}\right)$ is the radial base function, $d$ is the distance between points, 
$r$ is the softening factor and its value should be previously tested according to the data in each case; a very high value will generate a very softened surface, far from the real surface (García-León et al,2004).

\section{IX- TRIANGULATION WITH LINEAR INTERPOLATION}

This interpolation method uses the optimal delaunay triangulation. The algorithm creates triangles by drawing lines between data points. This method uses the reference points as the vertices of non- overlapping triangles that cover the interpolation areas. It is well known that the Delaunay triangulation is a unique solution for triangulation because it does not depend on the starting point, while other methods depend on the starting point of the triangulation (Lawson, 1977). The most common interpolation method on triangles is linear interpolation. A plane is defined in a rectangular coordinate system as shown in equation (14).

$$
Z=a_{00}+a_{10} x+a_{01} y
$$

\section{X-MOVING AVERAGE}

This method of interpolation involves simple averaging using a moving window such as an ellipse or circle. For each interpolated grid point a circle of specified radius is placed with its center at the grid point. The output grid node value is set equal to the arithmetic average of the identified neighboring data. If there are fewer than the specified minimum numbers of data within the neighborhood, the grid node is blanked (Yang et al., 2004).

\section{XI- DATA METRICS}

The collection of data metrics methods creates grids of information about the data on a node-by-node basis. The data metrics methods are not in general, weighted average interpolators of the Z-values (Yang et al., 2004). In the following descriptions, when computing the value of a grid node $(r, c)$, the local data set $S(r, c)$ consists of data within the specified search parameters centered at the specific grid node only (Y1lmaz, 2007). The set of selected data at the current grid node $(r, c)$ can be represented by $s(r, c)$ as in equation (15).

$$
S(r, c)=\left\{\left(x_{1}, y_{1} z_{1}\right),\left(x_{2}, y_{2} z_{2}\right), \ldots,\left(x_{n}, y_{n} z_{n}\right)\right\}
$$

Where $\mathrm{n}$ is the number of data points in the local data set.

\section{XII- LOCAL POLYNOMIAL}

The Local Polynomial method assigns values to grid nodes by using a weighted least square fit, with data within the grid node's search ellipse. The general form of this surface representation is given by equation (16) (Kidner et al., 1997):

$$
h_{i}=a_{00}+a_{10} x+a_{01} y+a_{20} x^{2}+a_{11} x y+a_{02} y^{2}+a_{m n} x^{m} y^{n}
$$

Where $h_{i}$ is the height of an individual point $\mathrm{i}, \mathrm{x}$ and $\mathrm{y}$ are its rectangular coordinates and $a_{00}, a_{10}, a_{01}, \ldots \ldots, a_{m n}$ are the coefficients of the polynomial. Since the coordinates of each vertex are known, the values of the polynomial coefficients can be determined from the set of simultaneous equations that are set up, one for each point. For any given point with known coordinates $x_{y} y$, the corresponding elevation can be determined by a substitution into this equation. 
Civil3D and ArcMap 9.1 softwares can build Triangulated Irregular Networks (TIN) surfaces as shown in figure- 3(a). TINs are, a specific type of terrain model common to Land Desktop and many other civil Engineering and surveying applications. TINs are preferable for profiles and cross sections based on the accuracy of their triangle-based model, but they are not necessarily visually pleasing. Grid surfaces and the other type that can be produced by Civil3D and ArcMap9.1, model a surface using quadrangles. Grid models tend to be visually smoother, but less accurate for engineering purposes.

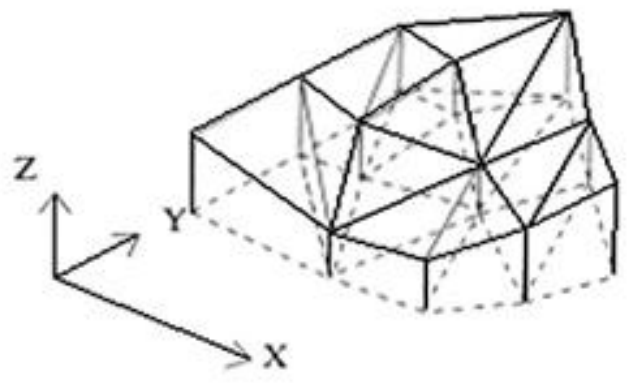

(a)

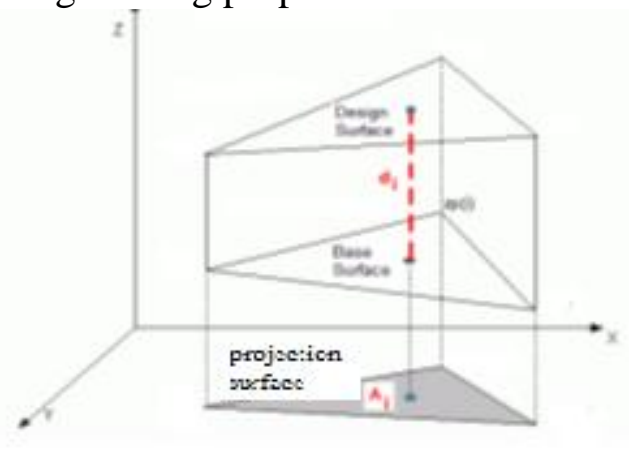

(b)

Fig. 3. Triangulated Irregular Networks(a) and prism with triangular(b).

Volume values are obtained from the differences between pre and post surfaces in excavation area. Excavation volume values for the areas that will be excavated in future are obtained from the

The volume $\mathrm{Vi}$ of a right prism with triangular (figure- 3(b)) base may be calculated starting from the projection surface (grey area) $\mathrm{Ai}$ and the distance di between the centers of mass of the two triangles as shown in equation (17).

$$
\mathrm{Vi}=\mathrm{Ai} \text { di }
$$

The total volume between the base surface and the tope surface may be calculated by summing the volume of all the prisms.

\section{RESULTS OF VOLUME COMPUTATIONS}

The purpose of this experiment was primarily to try spatial interpolation methods using Surfer, Civil3D, and ArcMap 9.1 softwares and report results and make comparison. To carry out the evaluation, the site was surveyed two times. The first was done on May, 2017 and the coordinates of 5910 points were measured and first 3D model was created. The second survey was done on July, 2017 after leveling the site, coordinates of 787 points were measured and the second 3D model was created. Figure- 4 shows the first observation, and figure- 5shows the second observation. The result of 3D model between first and second surveys of test area is shown in figure- 6. Figure- 7 shows the different levels in different colors. 


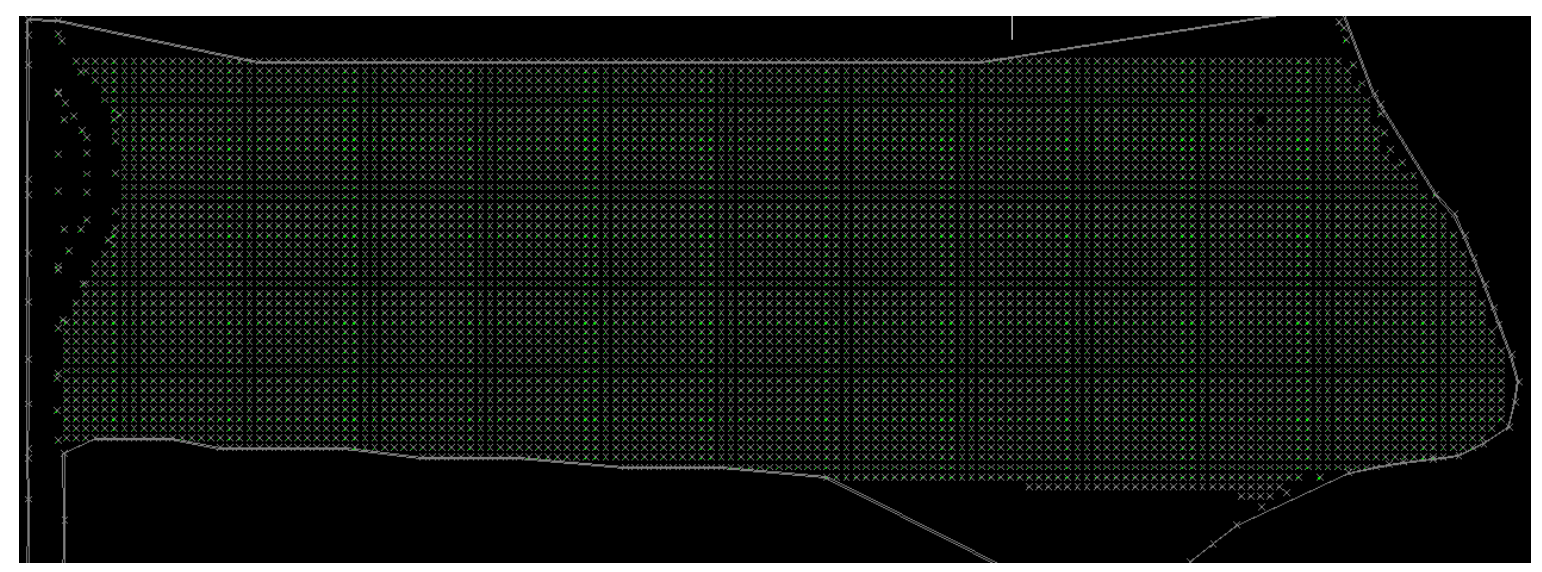

Fig. 4. Locations of the of $\mathbf{5 9 1 0}$ observed points, first observation.

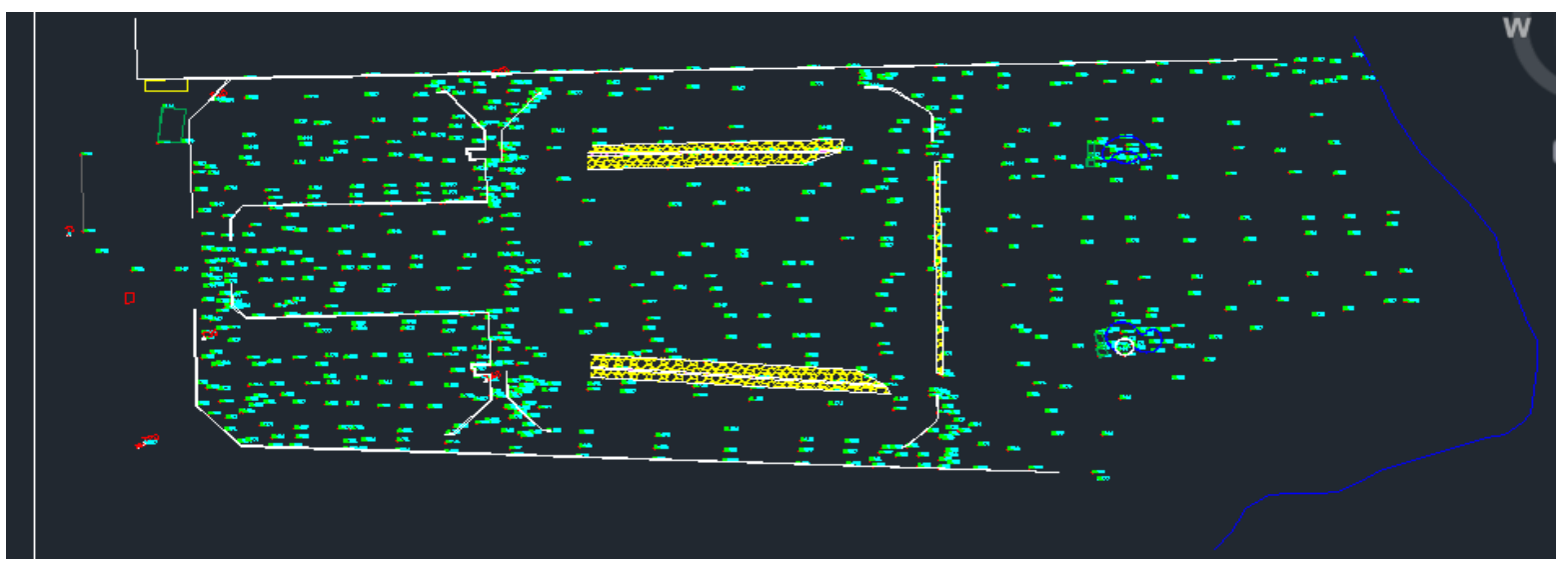

Fig. 5. Locations of the of 787 observed points, second observation.

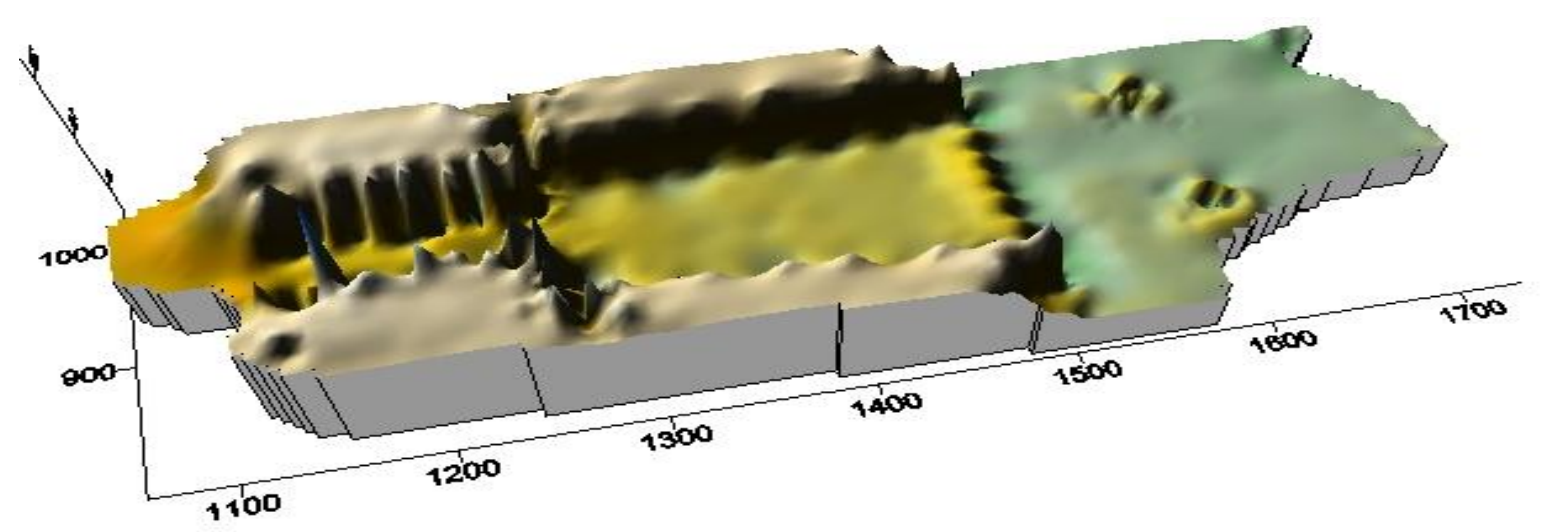

Fig.6. Three dimension models of test area. 


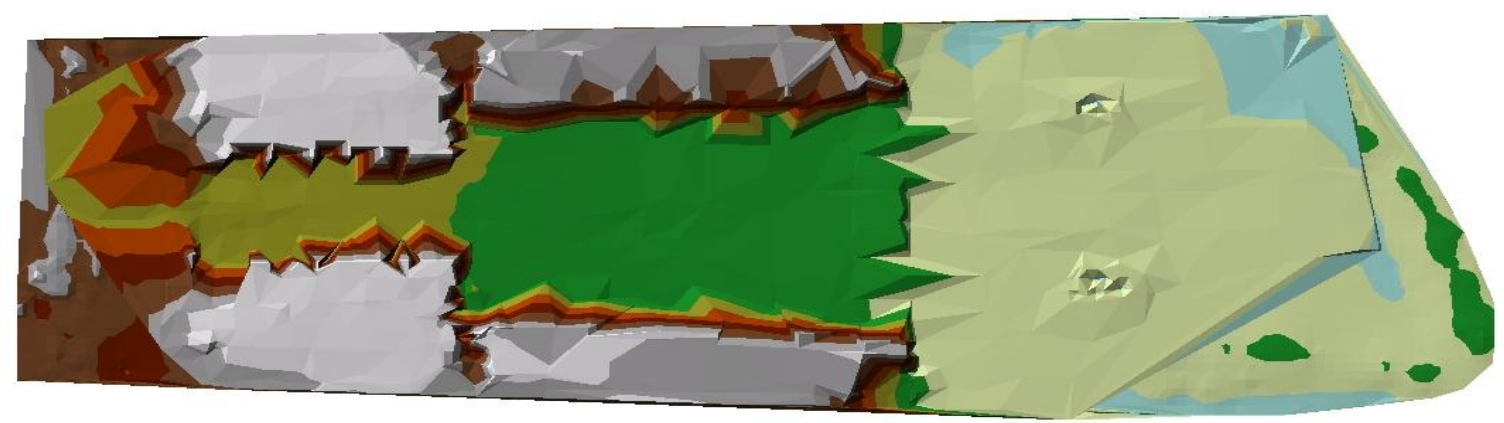

Fig.7. Three dimension models of test area in different colors.

Table 1. Volumes according to the interpolation methods.

\begin{tabular}{|c|c|c|c|c|}
\hline $\begin{array}{c}\text { Used } \\
\text { Software }\end{array}$ & Interpolation Method & $\begin{array}{c}\text { Cut Volume } \\
\qquad\left(\mathbf{m}^{\mathbf{3}}\right)\end{array}$ & $\begin{array}{l}\text { Fill Volume } \\
\qquad\left(\mathbf{m}^{\mathbf{3}}\right)\end{array}$ & $\begin{array}{l}\text { Net Volume } \\
\qquad\left(\mathbf{m}^{\mathbf{3}}\right)\end{array}$ \\
\hline \multirow{12}{*}{$\begin{array}{c}\text { Surfer } 8 \\
\text { Grid } \\
\text { volume }\end{array}$} & Data Metrics & 10 & 469,144 & 469,134 \\
\hline & Inverse Distance & 3,793 & 459,891 & 456,097 \\
\hline & Kriging & 5,861 & 448,278 & 442,417 \\
\hline & Local Polynomial & 2,797 & 466,953 & 464,156 \\
\hline & Minimum Curvature & 6,227 & 447,316 & 441,089 \\
\hline & Modified Shepard's Method & 26,002 & 457,463 & 431,460 \\
\hline & Moving Average & $\mathbf{0}$ & 552,346 & 552,346 \\
\hline & Natural Neighbor & 5,549 & 427,529 & 421,980 \\
\hline & Nearest Neighbor & 5,886 & 451,719 & 445,833 \\
\hline & Polynomial Regression & $\mathbf{0}$ & 462,467 & 462,467 \\
\hline & Radial Basis Function & 8,289 & 444,400 & 436,111 \\
\hline & $\begin{array}{l}\text { Triangulation with Linear } \\
\text { Interpolation }\end{array}$ & 5,668 & 447,592 & 441,924 \\
\hline Civil 3D & $\begin{array}{c}\text { Triangulation with Linear } \\
\text { Interpolation }\end{array}$ & 6,024 & 443,136 & 437,112 \\
\hline $\begin{array}{l}\text { ArcMap } \\
9.1\end{array}$ & $\begin{array}{l}\text { Triangulation with Linear } \\
\text { Interpolation }\end{array}$ & 6,048 & 441,167 & 435,119 \\
\hline
\end{tabular}

Volume is calculated with the 3-D surface analysis module in ArcGIS 9.1. For each altitude, the triangulated irregular network is examined to determine the volume of each triangle contained within the limits of that particular altitude. The sum of these triangles is used for the output of area and volume. Grid volume report with surfer when Grid volume computations are performed, the results are displayed in the grid volume report. The net volume is the sum of the positive volume (cut) and negative volume (fill). The cut volume is the volume of material in those places where the first surface is above the second surface. The fill volume is the volume of material in those places where the first surface is below the second surface. The fill minus cut is net volume.

Table 1 summarizes, the results obtained in this study. From the table, it can be seen that the cut volume equal zero when using data metrics, moving average, and polynomial regression methods. Also, cut volumes is very large $\left(26002 \mathrm{~m}^{3}\right)$ compared with other methods when Modified Shepard's Method was used. It can be also seen that the maximum and minimum net volumes are $552346 \mathrm{~m}^{3}$ (moving average method) and $421980 \mathrm{~m}^{3}$ (natural neighbor method). The difference between the two volumes is $130366 \mathrm{~m}^{3}$. This 
difference is equivalent to $28.6 \%$ of the average value of the volume. By excluding the above two methods, table 2 shows the net volumes and percent of difference from average when using surfer software. The percent of differences are ranging from $0.7 \%$ (Nearest Neighbor) to $4.5 \%$ (Data Metrics). The calculated net volumes by Inverse Distance, Kriging, and Triangulation with linear interpolation methods yielded close results with around 1.6 $\%$ from average net volume.

Table 2. Net volumes and percent of difference from average.

\begin{tabular}{|c|c|c|c|c|}
\hline $\begin{array}{c}\text { Used } \\
\text { Software }\end{array}$ & Interpolation Method & Net Volume $\left(\mathbf{m}^{\mathbf{3}}\right)$ & Difference $\left(\mathbf{m}^{\mathbf{3}}\right)$ & $\begin{array}{c}\text { \% of } \\
\text { difference }\end{array}$ \\
\hline \multirow{4}{*}{ Surfer 8 } & Data Metrics & 469,134 & $-20,065$ & -4.5 \\
\cline { 2 - 5 } & Inverse Distance & 456,097 & $-7,028$ & -1.6 \\
\cline { 2 - 5 } & Kriging & 46,417 & 6,652 & +1.5 \\
\cline { 2 - 5 } & Local Polynomial & 44,156 & $-15,087$ & -3.4 \\
\cline { 2 - 5 } & Minimum Curvature & 431,460 & 7,980 & +1.8 \\
\cline { 2 - 5 } & Modified Shepard's Method & 445,833 & 3,236 & +3.9 \\
\cline { 2 - 5 } & Nolynomial Regression & 462,467 & $-13,398$ & -3.0 \\
\cline { 2 - 5 } & Padial Basis Function & 436,111 & 12,958 & +2.9 \\
\cline { 2 - 5 } & Triangulation with Linear & \multirow{2}{*}{441,924} & 7,145 & +1.6 \\
\hline
\end{tabular}

Moreover, the results show the lowest discrepancies by using the Civil 3D and ArcMap 9.1software when applying the TIN method with around $1993 \mathrm{~m} 3$. This difference is equivalent to $0.5 \%$ of the average value of the volume from this interpolation method. The largest deference was between Surfer 8 and Civil 3D with around $4812 \mathrm{~m}^{3}$. This difference is equivalent to $1.5 \%$ of the average value of the volume in this interpolation method.

Finally, according to the theoretical concept of each method, the results values of volume are highly influenced by the geometry of the sampling points network. When using these methods, one must consider increasing the density of points sample used in gridding process. This is justifying the results by (Gao, 1997), sample density also had a significant influence on the accuracy of the Grid generated. We thought that unrealistic results of some methods is due to that the mathematical function of these methods is not appropriate for modeling such objects.

\section{CONCLUSIONS}

Forming a 3D model of the object requires 3D coordinates of number of points and applying the interpolation process with an appropriate function to these points. This study investigates the calculability objects with irregular shapes, which do not allow direct volumetric calculation, through 3D models. The main conclusions of the study are:

- The interpolation method has significant bearing on the values of interpolated heights from scattered data in Gridding process.

- Table 1 presents different interpolated calculated volumetric values of an irregular object surface which was reconstructed to this end and allows an indirect and sensitive volume calculation. Results in table 1 reveals that, the greatest difference in calculated volume was found when using the data metrics, moving average, modified shepard and polynomial regression methods. The difference in net volume reach to $28.6 \%$ when moving average and natural neighbor method methods were compared. 
- The reason for such results could be that the mathematical function of the Moving Average method is not appropriate for modeling such objects.

- Furthermore, it can be observed that the volumes obtained using Inverse Distance, Modified Shepard's Method, Nearest Neighbor, Kriging, Minimum Curvature, and Triangulation with linear interpolation methods are closed to each other.

- Each interpolation method has its own advantages and disadvantages and a particular interpolation method does not yield sound results from all aspects. Therefore, in accordance with the intended purpose of a study, it would be necessary to select an interpolation method yielding the object or landform models which best suit the original surface.

- Further study is recommended to investigate the effects of gridding spacing of the data used in modeling of an interpolation method which could yield better results in terms of volumetric accuracy.

\section{REFFERENCES}

1. Burrough PA, McDonnell RA (1998). Principles of geographical information systems. Oxford University Pres. New York.

2. Faul A.C. and Powell M.J.D. (1999). Krylov subspace methods for radial basis function interpolation. e 18th Biennial Conference on Numerical Analysis (Dundee), August, 1999.

3. Fencik R, Vajsablova M, Vanikova E (2005). Comparison of interpolating methods of creation of DEM. 16th Cartographic Conference. University of Defence Press. Brno, Czech Republic, pp.77-87.

4. Franke R, Nielson G (1980). Smooth interpolations of large sets of scattered data. International Journal for Numerical Methods in Engineering. Volume 15, Issue 11 November 1980 Pages 1691-1704.

5. Gao, J., 1997. Resolution and accuracy of terrain representation by grid DEMs at a micro-scale, International Journal of Geographical Information Science, Volume 11, Issue 2 pp:199-212.

6. García-León, J., Felicísimo A. M., Martínez J. J. (2004). A methodological proposal for improvement of digital surface models generated by automatic stereo matching of convergent image networks. http://www6.uniovi.es/ feli/pdf/ISPRS2004_1.pdf

7. Jang, D.W., Park, H.S., Choi, J.T., 2015. Selection of optimum spatial interpolation method to complement an area missing precipitation data of RCP climate change scenario. International Journal of Software Engineering and Its Applications, Volume. 9, No. 8 (2015), pp. 179-188 http://dx.doi.org/10.14257/ijseia.2015.9.8.16

8. Kidner D, Dorey M, Smith D (1997). What's the point? Interpolation algorithms within a regular grid DEM. 4th International Conference on GeoComputation. 25-28 July 1999, Mary Washington College, Fredericksburg, Virginia, USA.

9. http://www.geocomputation.org/1999/082/gc_082.htm

10. Lawson CL (1977). Software for C1 surface interpolation. In Mathematical Software III, Academic 7Pres, New York. 42 pages.

11. https://ntrs.nasa.gov/archive/nasa/casi.ntrs.nasa.gov/19770025881.pdf

12. Louie, John N. 2001. Gridding overview. http://crack.seismo.unr.edu/ftp/pub/louie/class/333/contour/surfer.html, 5 pages

13. Mike Price (2002). Deriving volumes with ArcGIS spatial analyst. ArcUser OctoberDecember 2002, 5 pages. http://www.esri.com/news/arcuser/1002/files/volumes.pdf

14. Nikolova N, Vassilev S (2006). Mapping precipitation variability using different interpolation methods. Proceedings of the Conference on Water Observation and Information System for Decision Support (BALWOIS). 25-29 May 2006, Ohrid, Macedonia. 
15. http://balwois.com/balwois/administration/full_paper/ffp-631.pdf

16. Pukanská, K., Sabová, J., Rusnáková, K., Gajdoš́́k, J(2008). Use of terrestrial laser scanning in detecting morphological changes of terrain. Coal-ore-geological survey, 15, 2008, 3, 28-31, ISSN 1210-7697.

17. Renka, R. J. 1988. Multivariate interpolation of large sets of scattered data. ACM Transactions on Mathematical Software 14, 2, 139-148.

18. Rick Ellis, (2012). A practical guide to AutoCAD Civil 3D 2012. A cadapult software solutions publication, 23 pages. https://www.cadapult-software.com/wpcontent/uploads/2013/05/APG_Civil_2012_TOC_Sample.pdf

19. Smith WHF, Wessel P (1990). Gridding with continuous curvature splines. In Tension. Geophysics 55(3): 293-305.

20. William I., Thacker J. Z. (2009). Algorithm XXX: SHEPPACK: Modified Shepard algorithm for interpolation of scattered multivariate data. Association for Computing Machinery, Inc..

21. Yang CS, Kao SP, Lee FB, Hung PS (2004). Twelve different interpolation methods: a case study of Surfer 8.0. XXth ISPRS Congress. Istanbul, Turkey, 778-785. http://www.isprs.org/istanbul2004/comm2004/comm2/papers/231.pdf

22. Yilmaz HM (2007). The effect of interpolation methods in surface definition: an experimental study. Earth Surface Proc. Landforms 32: 1346-1361. 